\title{
Optimization of a survey using spatially balanced sampling: a single-year application of clam monitoring in the Arcachon Bay (SW France)
}

\author{
Claire Kermorvant ${ }^{1,2, *}$, Nathalie Caill-Milly ${ }^{1}$, Frank D’Amico ${ }^{2}$, Noëlle Bru ${ }^{2}$, Florence Sanchez ${ }^{1}$, \\ Muriel Lissardy ${ }^{1}$ and Jennifer Brown ${ }^{3}$ \\ ${ }^{1}$ Ifremer, Laboratoire Environnement Ressources d'Arcachon, FED 4155 - MIRA, France \\ ${ }^{2}$ CNRS/Univ Pau \& Pays Adour, Laboratoire de Mathématiques et de leurs Applications de Pau-Fédération MIRA, UMR5142, \\ 64000 Pau, France \\ ${ }^{3}$ University of Canterbury, School of Mathematics and Statistics, Christchurch, New Zealand
}

Received 9 March 2017 / Received in final form 7 September 2017 / Accepted 16 September 2017

Handling Editor: Nicole Richoux

\begin{abstract}
Bivalves are important components of benthic marine and freshwater ecosystems throughout the world. One of the most exploited bivalves used for human consumption is manila clam (Venerupis philippinarum). In Arcachon Bay (SW France), commercial fishers and scientists have developed a monitoring survey to estimate clam stocks to assist in implementing a sustainable management strategy. The survey design that is currently used is based on standard stratified random sampling (StRS). The survey has been undertaken every 2 years since 2006. Each survey costs approximately $€ 50000$, with funding provided by $\sim 20 \%$ of the commercial fishers. The survey is quite expensive, given that this resource is managed mostly at a regional level. In 2016 for instance, the survey was not done because of a shortfall in funds to support it. Recent studies on survey designs have focused on new developments that allow for higher statistical efficiency (lower sampling error) coupled with lower survey effort. Among these is the spatially balanced generalized random tessellation stratified (GRTS) design. The aim of this study is to compare the performance of the common StRS method with the GRTS design. To do this, we created a semi-virtual clam population by extrapolating the 2012 field survey results in the whole bay and simulated survey events with the two designs. We then assessed the two survey designs using three threshold precision levels $(5 \%, 10 \%$ and $20 \%$ precision) for the two estimators of interest (biomass and abundance). We recommend the use of the GRTS design for clam surveys in Arcachon Bay. To achieve the same level of precision, GRTS requires less survey effort than StRS.
\end{abstract}

Keywords: Venerupis philippinarum / bivalve / simulation / survey / Arcachon Bay / GRTS

\section{Introduction}

Manila clam (Venerupis philippinarum) is one of the most exploited bivalves in the world and stocks are of concern in many locations. Because of the interest in the species, many studies have been carried out. For example, work has been done with the aim of assessing the geographic spread of these species (which can be invasive), such as in Poole Harbour in the UK (Jensen et al., 2004), San Francisco Bay, USA (Carlton et al., 1990), Venice Lagoon, Italia (Pranovi et al., 2006), Southern California, USA (Talley et al., 2015) and Santander

\footnotetext{
*Corresponding author: claire.kermorvant@univ-pau.fr
}

Bay, Spain (Bidegain et al., 2015). Others studies have been undertaken to focus on factors influencing mortality in Manila clam stocks (Park and Choi, 2001; Paillard et al., 2004), to study hyperparasites (Le et al., 2015) and to report ingestion of microplastics (Davidson and Dudas, 2016).

Despite the number and diversity of studies, there is no standardized design for bivalve sampling for population estimates. The studies cited above use different survey designs, each with different features such as randomized or stratified designs, quadrats or transect sample units, and once-off data collection surveys, or ongoing repeated field surveys, etc. Interestingly, none of these studies has reported problems caused by the survey design, except for one (Davidson and Dudas, 2016), which mentioned a potential limit in precision 
from having a small sample size. Many of these studies of Manila clam use a probability-based design, usually stratified random sampling (StRS) (James and Fairweather, 1996; Pitel et al., 2004; Bald et al., 2005; Gray et al., 2014; Gray, 2016a, b). Others have used expert knowledge rather than a probability sample to locate sample sites. Sample designs not based on probability lead to a number of problems including lack of repeatability and the difficulty in estimating a valid measure of precision. This could lead to biased estimates (Albert et al., 2010).

A fundamental reason for design-based sampling is that the a priori determination of inclusion probabilities allows for unbiased statistical inference (Särndal et al., 1978; Thompson, 2012).

In France, Arcachon Bay represents, along with the Morbihan Gulf, the main Manila clam production area. Manila clam in Arcachon Bay have been studied since the 1990 s to provide information on the species predators, mortality for species management (Robert et al., 1993), and to identify suitable areas for Manila clam harvesting in the Bay (Robert et al., 1993). Later, after abandoning the culture and installation of clams in the bay (Auby, 1993), studies have been more oriented towards pathology (De Montaudouin et al., 2000) and, starting in 2003, stock surveys (Caill-Milly et al., 2003).

Today, monitoring of the fishery stock is a co-management approach between commercial fishers and scientists. Surveys have been undertaken every 2 years since 2006 The surveys are conducted to assess selected indicators (densities, total number of clams expressed in number and mass, size structure, etc., for details, see (Caill-Milly et al., 2006, 2008; Sanchez et al., 2010, 2012 2014)) of the current stock and to detect any changes in these indicators over time. This information is the basis for adaptive management measures (e.g. issuing licences, defining protected areas, and identifying periods of no fishing). As there is no quota defined for this fishery, catch control can be made through the number of licences issued. If the indicators show a decline in the population, this number of licences is subsequently revised downward. Other options are to impose periods when fishing is banned, and extending any protected areas. In this last example, accurate spatial data are mandatory for the choice of the protected areas, for example to select areas with sufficient densities, and containing a large proportion of adults.

A major concern with this last monitoring survey is that it is time-consuming (approximately 500 sample stations are visited on each survey) and costly, although the aim is to keep the biennial survey costs under a threshold of $€ 50000$. Without the support (financial and in kind) of the commercial fishers, ongoing surveys are not assured. This indeed happened in 2016 and no surveys were undertaken. This lack of a survey in 2016 present new problems with reporting on the fisheries stock because there is no longer an unbroken time series of the stock status indicators to use in assessing population management measures. The Arcachon Bay monitoring survey is of particular importance because the clam population shows lower fitness compared with other French sites (De Montaudouin et al., 2010, 2015). Therefore, it is very timely and even necessary in this context to consider alternative monitoring survey designs that are less costly but do not compromise survey precision.
To monitor the state of the stock, the StRS method has been used for the Arcachon Bay's clam monitoring (Caill-Milly et al., 2003, 2006, 2008; Sanchez et al., 2010, 2012, 2014) because it is viewed as the more powerful among classical sampling designs using strata. This survey design has already been used in the Morbihan Gulf (Berthou et al., 1997) and has provided information that has been accepted by both the science and fisheries communities. The main disadvantage of this design is that sometimes areas of the bay are not surveyed because there is no explicit spatial structure imposed on the sample locations within strata (Stevens and Olsen, 2004; Christianson and Kaufman, 2016).

Given these well-known caveats and weaknesses of StRS, new spatially balanced sampling designs have been developed for monitoring ecological resources (Stevens and Olsen, 2004; Robertson et al., 2013; Brown et al., 2015). This presented an opportunity to review the use of the generalized random tessellation stratified (GRTS) spatially balanced design as an alternative to the current StRS used in the Arcachon Bay clam monitoring survey.

Survey design starts with setting targets for total effort and desired precision of the survey estimates; priority can be given to either maximize precision or minimize total effort (GuilleraArroita et al., 2010). To formulate a survey design, the sampling practitioner must be aware of the trade-offs among objectives (Stehman and Overton, 1994), indeed, no survey design will be ideal for all purposes (Kenkel et al., 1990). For example, James and Fairweather (1996) explained that overly small sample sizes will not provide precise descriptions of beach macro-fauna species because the survey may fail to consider all sources of uncertainty, confounding large- and small-scale variation.

In this paper, we assess clam monitoring survey performance in Arcachon Bay, contrasting two survey designs: StRS, the current design, and GRTS. Using a semi-virtual population created from the results of a real survey (2012), we compare the performances of these two survey designs in terms of precision and survey effort. Finally, we estimate the impact of differences in sample size on the overall survey cost.

\section{Materials and methods}

\subsection{Studied species description: biological and ecological aspects}

Three different clam species are found in Arcachon Bay: the cross-cut carpet shell (Tapes decussata), the golden carpet shell (Paphia aurea) and the Japanese carpet shell ( $V$. philippinarum) (Bertignac et al., 2001). V. philippinarum, also called "Manila clam", is the most abundant species among them. It can tolerate salinities from 15 to $50 \mathrm{~g} \mathrm{~L}^{-1}$ (Le Treut, 1986), but their growth is highly determined by temperatures and trophic resources (Melià et al., 2004; Tamayo et al., 2015). Other environmental factors can also have an impact on growth and survival, such as turbidity, immersion time, sedimentary characteristics, dissolved oxygen concentration and parasites (Goulletquer and Bacher, 1988; Soudant et al., 2004; Gosling, 2008). With $V$. philippinarum, growth does not stop during winter, unlike the other two species. This capacity allows Manila clam to reach an exploitable size very quickly (3 or 4 year) and makes this species cost-effective to harvest 


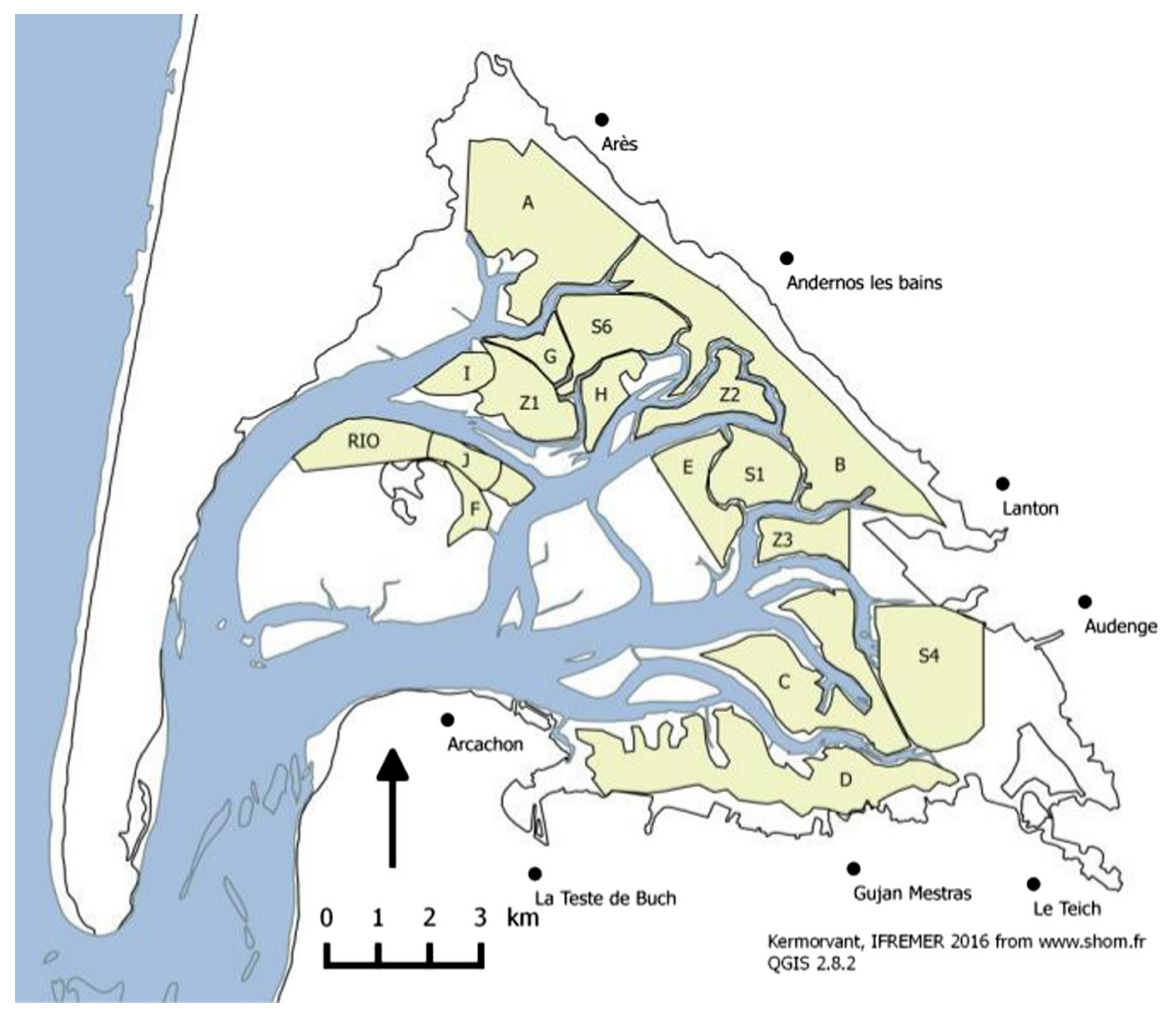

Fig. 1. Survey site, Arcachon Bay, France, divided into 17 strata (A, B... RIO... Z3).

(Le Treut, 1986). Research on the Arcachon Bay clams highlights a growth deficiency above $32 \mathrm{~mm}$ (Caill-Milly et al., 2012). This is not the case in other French or foreign production sites (Dang, 2009; Caill-Milly et al., 2012). Manila clams are sexually mature from $20 \mathrm{~mm}$ and can reproduce several times a year.

Manila clams' natural habitat comprises the medio-coastal fringe of sheltered bays, estuaries and river mouths. They favour areas with low swell and preserved areas which create frequent water renewal (Le Treut, 1986). Manila clams are benthic bivalve and live buried in the soil at a variable depth of $7-12 \mathrm{~cm}$, depending on size and season, with the adults living deeper than juveniles. The environmental conditions such as regularity and duration of water flow, temperature, and the thickness and porosity of sediments have a direct influence on this clam micro-distribution (Olu et al., 1996). Earlier, Walker and Tenore (1984) found that Manila clam density varies widely depending on sediment sub-substrates. Their results match the ecological preferences of clams found by Tamura (1970), who cited an ideal living environment composed of $20-60 \%$ sand and $20-30 \%$ mud.

Manila clams have an aggregative type of spatial distribution (Kalyagina, 1995). This has been confirmed by many studies which also emphasized high spatial variability, regardless of the scale or the method of sampling (Juanes et al., 2012). This species can have lateral movements reaching $6 \mathrm{~m}$ per month (Tamura, 1970). Its vertical distribution within sediment varies between year's periods and depends on individual age: juveniles are found near the surface whilst adults dwell at depth ranging between 7 and $12 \mathrm{~cm}$, the latter being the maximal burrowing depth known so far (Le Treut, 1986).

\subsection{Study area: the establishment of a survey design}

\subsubsection{Objectives}

Manila clam production in Arcachon Bay is important, with more than $500 \mathrm{~T}$ produced per year (Sanchez et al., 2014). In 2016, 41 commercial fishers depended directly on this harvest. In addition to this commercial activity, recreational exploitation of the Manila clam resource in Arcachon Bay takes place. Management strategies such as limiting the number of licences and established no-fishing protected areas have been used since 1996 to reduce over-fishing. To measure the impact of such management strategies, commercial fishers and scientists rely on information from stock assessments.

\subsubsection{Study area: environmental characteristics}

Arcachon Bay is a $156 \mathrm{~km}^{2}$ semi-sheltered lagoon in the southwest French coast (Fig. 1). Mostly composed of intertidal flats $\left(110 \mathrm{~km}^{2}\right.$ within the inner lagoon $)$, this mesotidal system has a sediment composition ranging from mud to muddy sand and is colonized by extensive sea grass meadows of Zostera noltei (Auby and Labourg, 1996; Kombiadou et al., 2014). Influenced by external neritic waters and continental inputs (Dang, 2009), the bay has a semi-diurnal macro-tidal rhythm. Temperature and salinity gradients within the bay are controlled by these water mass characteristics as well as by slow tidal water renewal (Bouchet et al., 1997; Plus et al., 2006). The Manila clam population is primarily located in an arc from west to south within the bay on its east side, in an area covering $\sim 50 \mathrm{~km}^{2}$.

The primary area of location of $V$. philippinarum was divided into strata based on expert knowledge (fisheries 
scientists and commercial fishers). Each stratum represents an area that is as homogenous as possible (Yoccoz et al., 2001; Zhao et al., 2016) (Fig. 1) in terms of hydrology, sediment particle size characteristics, current patterns. This stratification was chosen because these factors were considered to be the most relevant for partitioning the spatial distribution of Manila clam. The stratification was mapped in the initial monitoring survey. Over time new strata in adjacent areas have been added, while some of the original strata are no longer sampled. In 2014, there were 17 strata in the survey. Previous to this there were 14 strata (from 2003 to 2006), 16 strata (from 2008 to 2010) and 19 strata in 2012.

\subsection{Monitoring surveys: classical methodology and new approach}

The current survey design involves sampling at high tide using a Hamon grab aboard a professional boat. The Hamon grab is the recommended tool for sampling benthic macrofauna from coarse substrata (Le Treut, 1986). It is regularly used on rough ground (Kingston, 2009) and works well for sampling at the depth the Manila clam is buried at. Manila clams live buried at a mean of $12 \mathrm{~cm}$ of depth and the grab collects a sediment core of $0.25 \mathrm{~m}^{2}(0.5 \mathrm{~m} \times 0.5 \mathrm{~m})$ on a $0.2 \mathrm{~m}$ depth. For this study, we will suppose that the sampling gear does not involve sampling bias. The core samples are filtered on board with running water over a set of three sieves with 2,1 and $0.5 \mathrm{~cm}$ mesh size. All specimens of Veneridae are sorted and identified. Counting and measurement (to the nearest $1 \mathrm{~mm}$ using a slide calliper precision) are undertaken on board or in the laboratory, depending on the year.

Surveys have been performed every 2 years since 2006 in late spring (and was undertaken every 3 years between 2003 and 2006) (Sanchez et al., 2012). The whole field survey, including prior requirements, typically takes 18 days. The survey effort is 10 stations per $\mathrm{km}^{2}$ (each sample station being identified by its geographic coordinates). Stations are randomly located within each of the strata. This gives a proportional stratified sampling, with a survey effort proportional to the strata surface size.

Stratified sampling is one of the most used designs in ecology. StRS is one of the most commonly used survey design in ecology, due to its ease of use and its flexibility. Additional samples can be easily added at the survey design a posteriori. The StRS technique involves dividing the study area in strata then randomly sampling within each stratum. For a better performance, individual stratum are created to be relatively homogeneous (Yoccoz et al., 2001; Zhao et al., 2016). Recently, there have been a number of new spatially balanced survey designs that are becoming more popular (e.g. Stevens and Olsen, 2004; Robertson et al., 2013; Brown et al., 2015). One of the first spatially balanced designs was GRTS, designed for environmental monitoring over the long term and at a large scale (Stevens and Olsen, 1999, 2003, 2004). The spatial balance provided by the GRTS design addresses a major disadvantage of StRS for our population. With GRTS, no sample station will be excessively far from another station (in this, it resembles but surpasses the systematic sampling strategy) and very few stations will be extremely close to another. Importantly, GRTS is known to have high efficiency compared with other designs. As with StRS, the main area can be divided in strata but the main difference is that GRTS use an algorithm for spatial balance instead of a simple random process.

GRTS has been used in several studies. For example, it has been used to determine bull trout (Salvelinus confluentus) population status through counts in basins of the Columbia River Plateau in the USA (Jacobs et al., 2009) and to develop ArcGIS tools via a forest biodiversity survey in a case study in Hunan Province, China (Li et al., 2012). Here, we illustrate the use of GRTS, and provide a comparison with StRS for bivalve surveys.

\subsection{Methodology for comparing two survey designs and choosing the best way to sample the clam population}

The performances of both the GRTS and StRS were evaluated using estimators of total abundance based on the hypothesis of a known population (virtual one) of Arcachon Bay Manila clams.

The survey design comparison followed these classical steps: (i) the studied variable distribution was considered to be known in the population; (ii) samples were selected from this population with both designs and results compared.

\subsubsection{Building the Arcachon Bay clam population}

In this study, a single-year dataset was used (2012), but this methodology can be applied to the five other datasets (2003, 2006, 2008, 2010 or 2014).

The spatial distribution of clam abundance (expressed in number per $0.25 \mathrm{~m}^{2}$ ) and biomass (expressed in grams per $0.25 \mathrm{~m}^{2}$ ) was estimated for the year 2012 from survey data. We used geostatistical analyses and a kriging technique from the RGeosta ts library (Renard et al., 2014) in the R environment (R Core Team, 2014) to create a semi-virtual population of clams. The analysis had the following steps: (1) exploratory data analysis; (2) variography analysis with adjustment of a model to the experimental variogram (nugget effect and isotropic exponential model) and (3) global assessment and associated variance. The implemented interpolation method used was block kriging model with a $200 \mathrm{~m}$ sliding neighborhood. This methodology created a model (usually a smoothing model) to build a complete semi-virtual population. It used the observed clam data from the sample sites to "fill in" the missing data from the sites that were not sampled. Figure 2 presents the virtual populations created for clam abundance and biomass. The kriging settings were chosen according to expert knowledge, this could bring some bias in results. But as the same semi-virtual population is used to assess the performance of both survey designs we decide to not take it into account.

\subsubsection{Performance assessment: the optimal number of sample stations per design and the corresponding precision}

We decided to compare the two survey designs in terms of the optimal number of samples within each stratum which is directly linked to the cost. Here, we define the optimal sample size as the minimal number of samples that need to be collected in each stratum to achieve the desired precision of the clam 

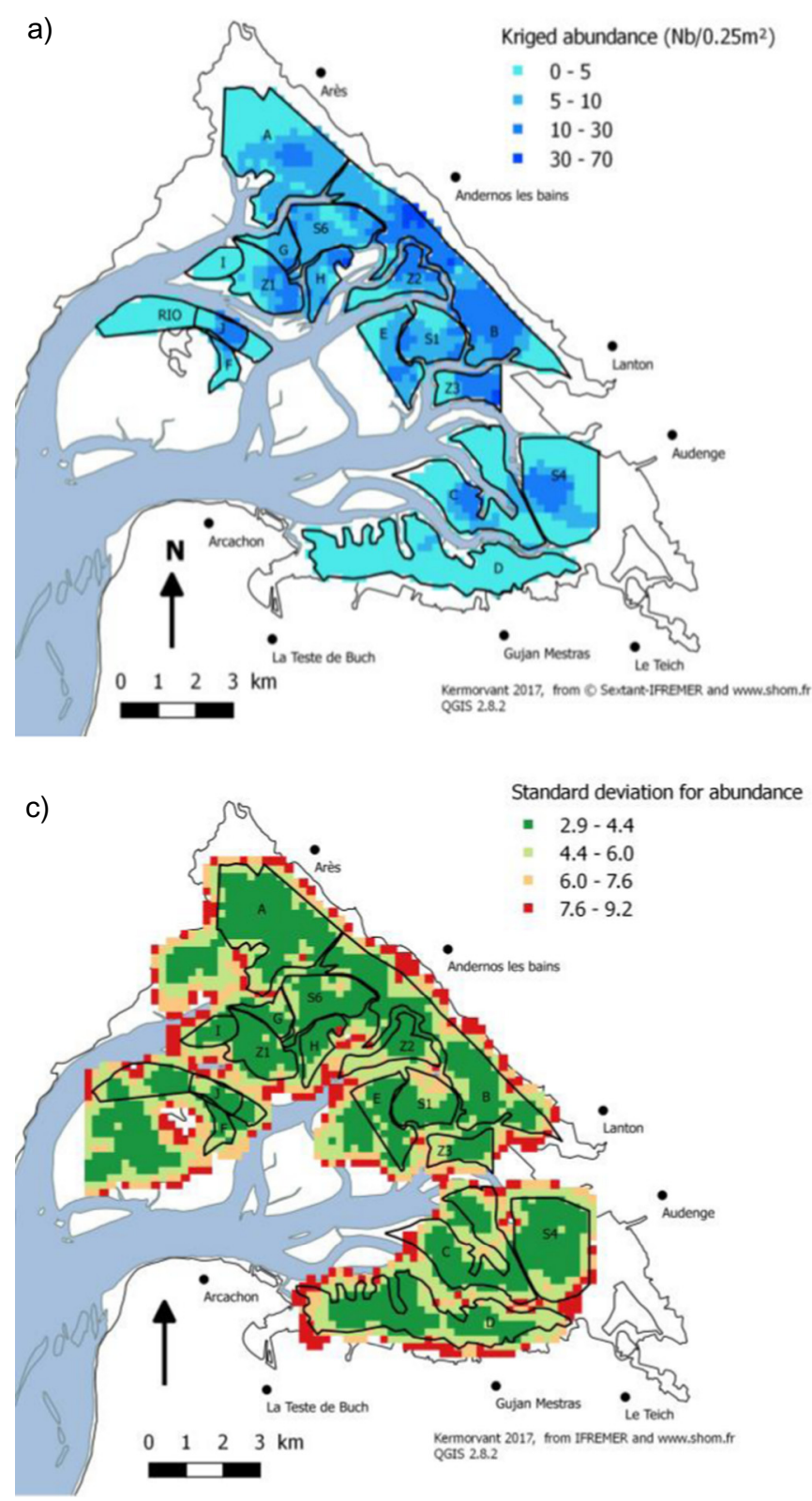

Fig. 2. Semi-virtual clam populations for abundance (a) and biomass

population estimate. To determine this, selection of the GRTS and StRS points was performed by using a statistical sampling methodology with the "spsurvey" and "sp" packages in R software, respectively (Pebesma and Bivand, 2005; Bivand et al., 2013; Kincaid and Olsen, 2015).

MacKenzie (2006) defines Accuracy $=\mathrm{MSE}=$ variance + bias $^{2}$. As StRS and GRTS are probabilistic survey designs, every sample has a known non-zero probability of selection, leading to unbiased estimates of the mean and variance (and their confidence interval) for variable of interest (Albert et al., 2010). Also, bias can be considered as null when the sampling is repeated many time and thus accuracy become synonym of variance.

The steps to determine precision of estimations by survey design and then compare their performances were as follows:

Step 1: For a given size $n(n=1,2,3, \ldots, N)$ of sample stations within each stratum, we took 1000 different samples
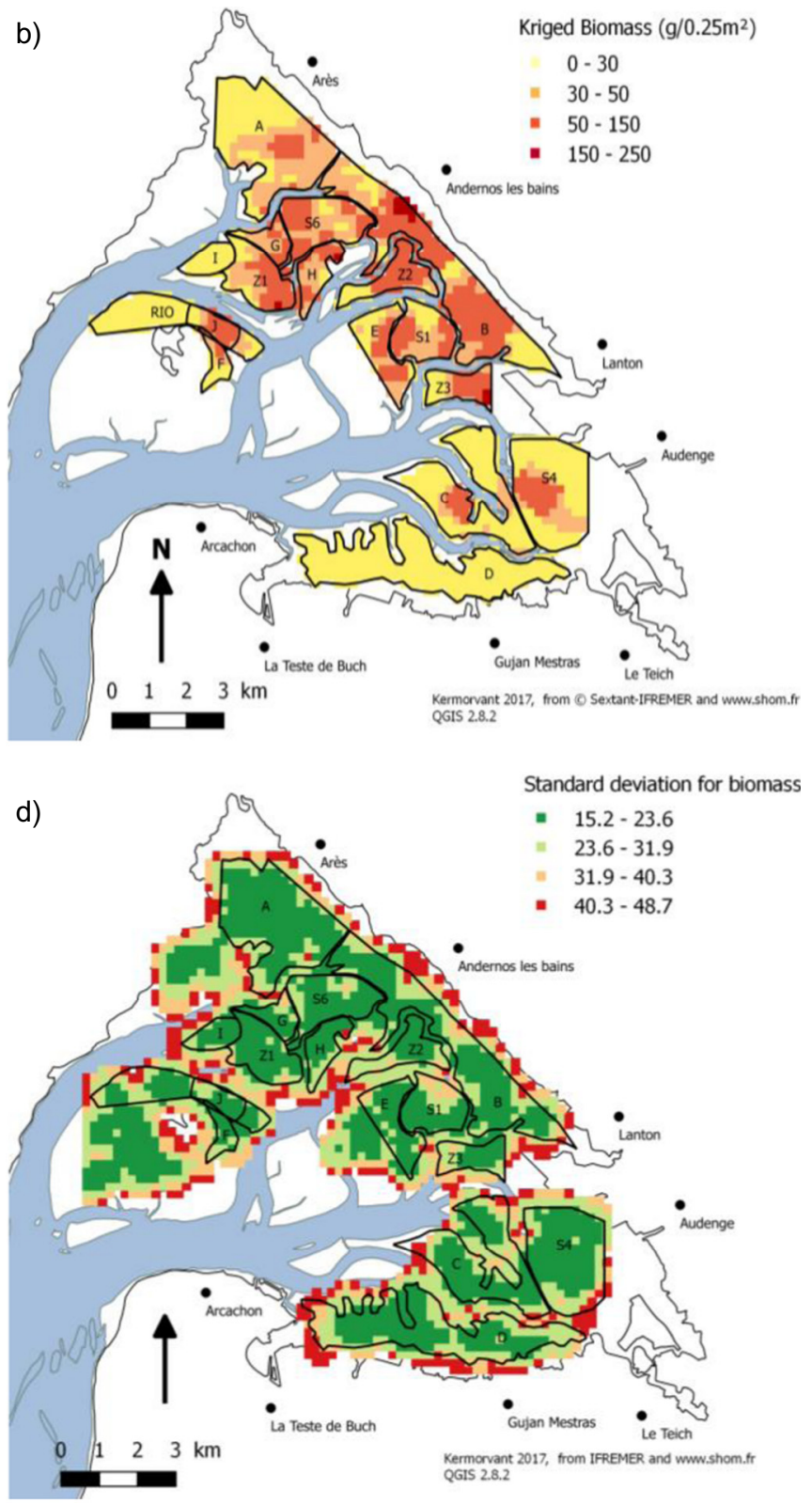

(b) parameters and associated standard deviation (c and d).

for GRTS and for StRS. Each sample at the given survey effort is called a replicate. The same number of stations, $n$, was chosen within the stratum, first using the StRS design and then the GRTS design.

Step 2: For each replicate sample $j(j=1,2,3, \ldots, 1000)$, at each level $n$ of survey effort, the mean biomass and mean abundance were estimated, and the confidence interval (95\%) of the estimated mean biomass and the estimated mean abundance were computed. The width of the confidence interval and the relative precision of the estimators of the two designs were calculated as:

$$
e_{j n}=2 z \times \frac{s_{j n}}{\sqrt{n}}
$$

where $z$ is the quantile of the standard normal distribution $(1.96$ for a $95 \%$ confidence interval) $n$ is the survey effort within the 


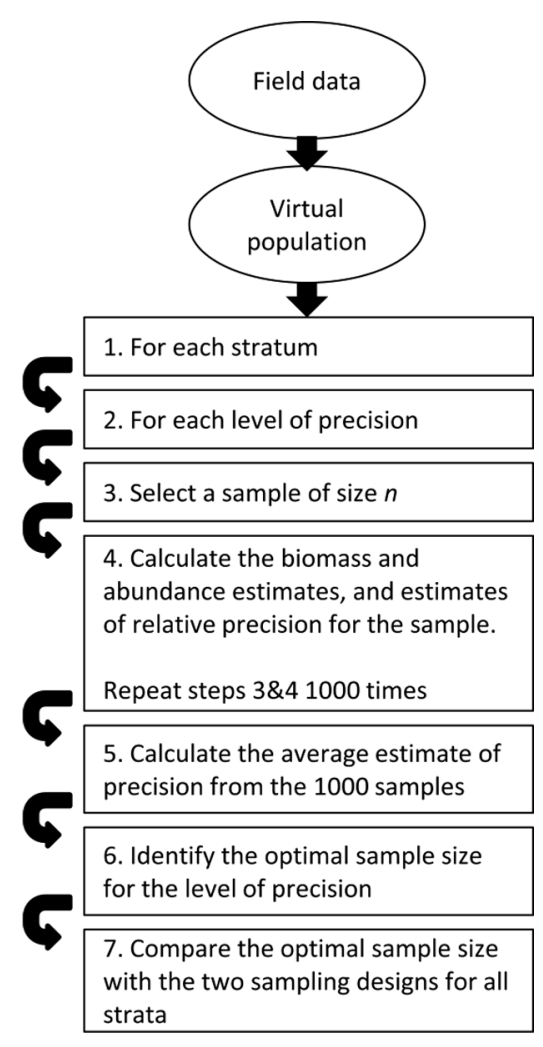

Fig. 3. Methodology used to assess the performances of StRS and GRTS on Arcachon Bay manila clam population.

stratum and $s_{j n}$ is the standard deviation of the within-stratum sample with a sample size of $n$ for replicate $j$. Then, for each replicate $j$, the precision was calculated as:

$$
P_{j n}=\frac{e_{j n}}{\bar{x}_{j n}} \times 100,
$$

where $e_{j n}$ is the confidence interval width and $\bar{x}_{j n}$ is the estimated mean (biomass or abundance). The overall precision for the stratum for the sample size $n$ was calculated as the average of the 1000 estimate of precision:

$$
P_{n}=\frac{\sum_{j=i}^{1000} P_{j n}}{1000} .
$$

Step 3: The sample effort was varied within the stratum until three levels of nominal precision for biomass and for abundance $\left(P_{n}=20 \%, 10 \%\right.$ and $\left.5 \%\right)$ were achieved for the two survey designs. We defined this as the optimal sample size per stratum for a given level of precision. As there was a difference in the optimal size for estimating biomass compared with abundance, we selected the larger of the two sample sizes as the value for the corresponding stratum.

Step 4: Comparison of the two methods was carried out using statistical tests and by comparing the optimal sample sizes. We calculated paired Wilcoxon tests to evaluate the significance of the differences in the optimal sample sizes of the GRTS and StRS methods for the different precision levels. Tests were conducted with the R software, "stats" package (R Core Team, 2014).

This methodology is summarized in Figure 3. Back to a practical point of view: assessment of monitoring cost
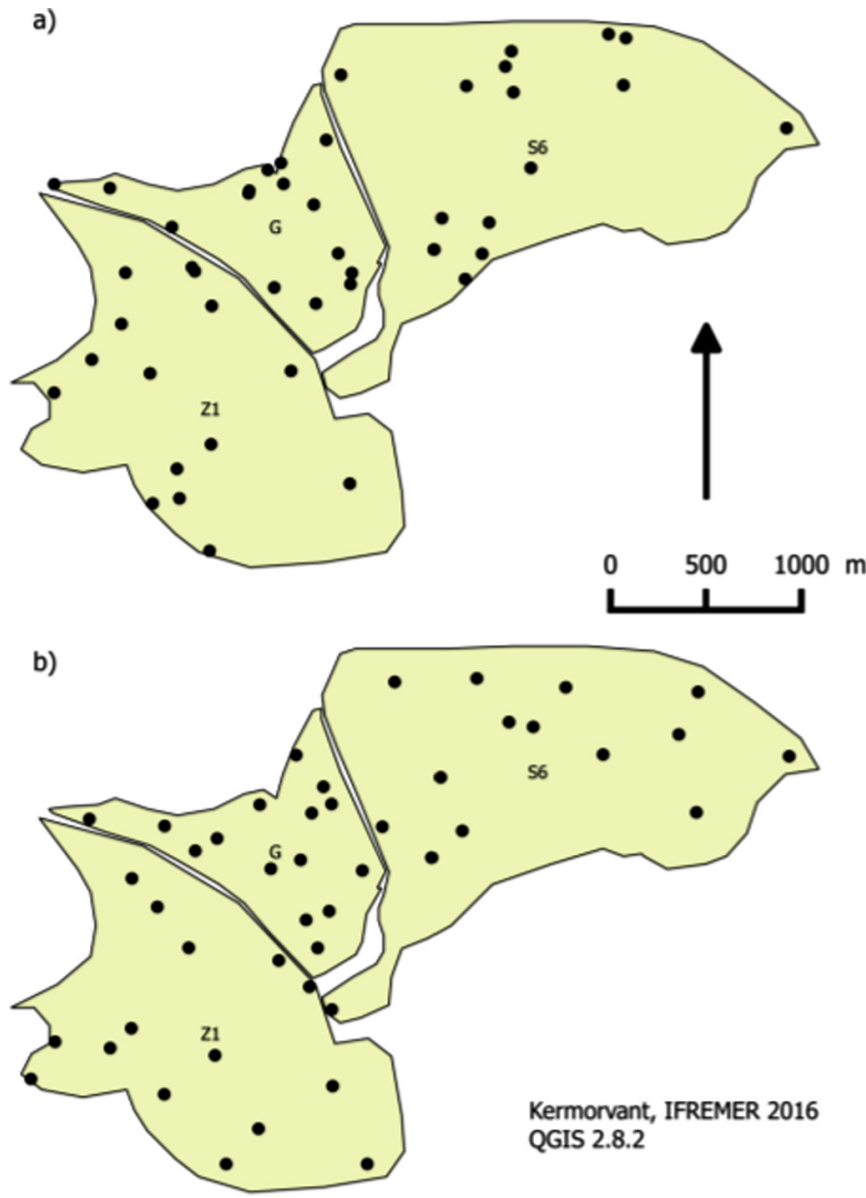

Fig. 4. Examples of sampling plans with 15 sample units per stratum for the stratum S6, Z1 and G using (a) StRS design and (b) GRTS design.

We based our calculations on the 2012 field survey budget to assess the survey costs. The survey cost was decomposed into two parts: a fixed cost (the costs of meetings to prepare the survey, material, data treatment, meetings to present the results to the commercial fishers and administration, etc.) and a variable cost which depended on the sample size (the costs of boat and grab rental, participation costs of scientists and commercial fishers, etc.). We estimated the fixed cost to be $€ 12000$ and the cost of one sample was approximately $€ 80$. We assessed the overall cost of the simulated designs as follows:

Surveycost $=$ fixed cost + number of samples $\times 80$.

\section{Results}

Three main outcomes are presented: a map of GRTS and StRS applied in the same strata to visually observe the differences in their survey plan, then a comparison using the optimal sample size and finally a comparison using the field price.

\subsection{Visually comparing the designs}

To compare the spatial distribution of the two survey designs, we show (Fig. 4) an example of plans obtained from a 

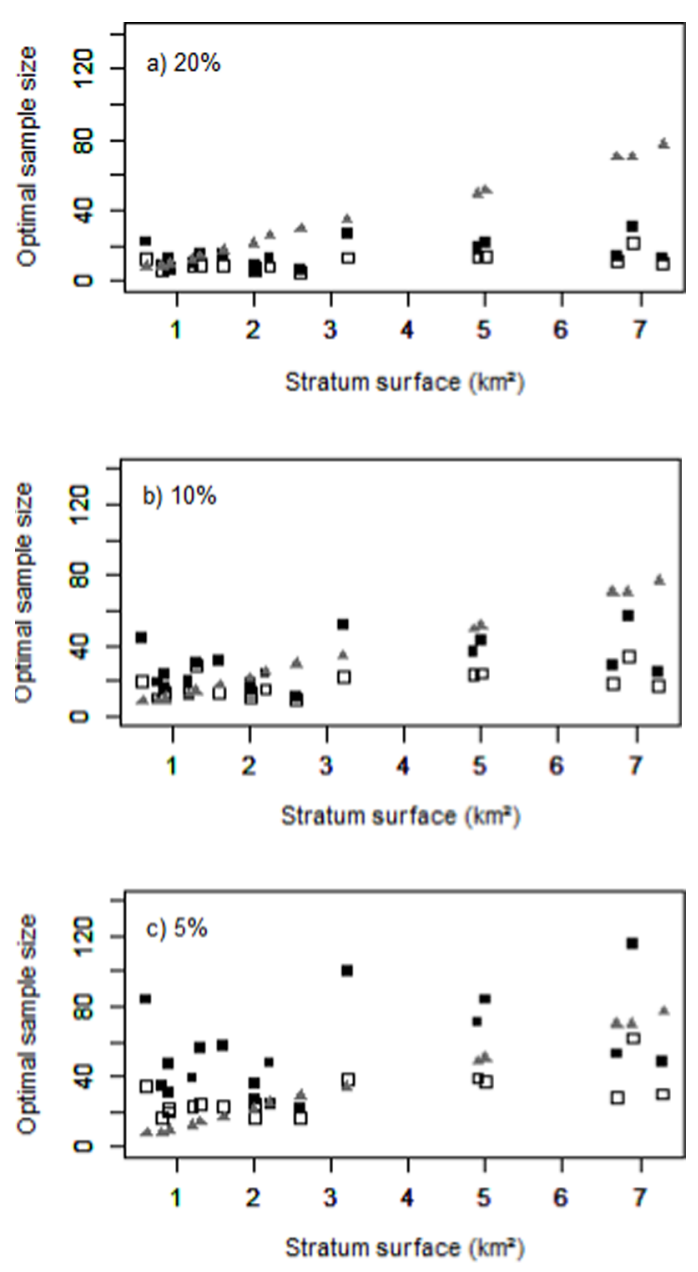

Fig. 5. Optimal sample size estimated for the StRS and GRTS designs by stratum surface with three precision thresholds: (a) $20 \%$, (b) $10 \%$ and (c) $5 \% . \Delta=$ actual number of stations surveyed during the 2012 campaign; - =estimated optimal sample size using StRS, $\square=$ estimated optimal sample size using GTRS.

single StRS and a single GRTS survey, with the same survey effort of 15 samples in three strata (G, Z1 and S6). In this part, only one random sample was used for both designs and mapped.

The two survey maps illustrate one important feature of the benefit of GRTS, which is that it will always produce a sample that is well-balanced, and with more complete spatial coverage. In Figure 4a, there are noticeable clusters of sample points and areas devoid of samples. With GRTS (Fig. 4b), there is more consistent or even coverage of samples, without having a fixed regular pattern of sample points. In Figure $4 \mathrm{~b}$ the sample points still appear to be randomly located without either extreme regularity or extreme clustering.

\subsection{Comparing the optimal sample size of each design}

The optimal sample sizes for the three levels of precisions for estimates of biomass and abundance for each stratum are displayed in Figure 5.
The optimal sample size for GRTS and StRS appears to be unrelated to the size of the stratum. The most prominent feature of the graphs in Figure 5 is that fewer samples were needed with GRTS than with StRS to achieve the same level of precision. The difference in the optimal sample size for GRTS compared with StRS was most pronounced for the more precise surveys (Fig. 5a). The differences in the optimal sample size between GRTS and StRS for the different levels of precision were all significant (Tab. 1).

\subsection{Comparing the survey costs of the designs: highlighted issue}

We used the optimal sample sizes for the three target precision levels described in the previous section to estimate the total survey costs (Tab. 1). The total sample size for GRTS and StRS was estimated from the sum of the individual strata observed using the optimal sample size (Tab. 1). The 2012 total sample size and cost are also shown.

Given the reduced number of sample points for the same level of precision, in our study, GRTS always costs less than StRS. Further cost savings can be made by reducing the targeted precision level; for example, at $5 \%$ precision with GRTS, the total cost of the survey would be $€ 50000$ and half that cost if only $20 \%$ precision was acceptable. Interestingly, even with the highest level of precision we used $(5 \%)$, the cost of the total GRTS survey would be less than that of the 2012 survey.

\section{Discussion}

Monitoring survey designs should be designed to accommodate the end-users' requirements for precision or performance of the survey results, and the cost budget (Yoccoz et al., 2001; MacKenzie and Royle, 2005; Guillera-Arroita et al., 2010; Moore and McCarthy, 2016). In practice, this often translates to questions such as the allowed or permissible maximal imprecision, and the maximum allowable survey cost. For these fisheries, these two requirements are both priorities. In 2016 and 2017, for example, the clam survey did not occur in Arcachon Bay because the commercial fishers could not afford it. Therefore, there is some urgency to find a more cost-effective design where the survey results have enough precision to be able to contribute to the clam management strategy.

We have developed a methodology to assist commercial fishers to test design surveys. The desired level of precision for the survey can be set along with a variable cost component. The use of a simulation study allowed us to test a panel of different levels of precision and compare two survey designs. This simulation approach has been used in many other studies. For example, simulations were used in an instrument-based survey to evaluate alternative survey designs for Arctic marine mammal populations (Conn et al., 2016) and to optimize animal detection given the breeding behaviour and logistical access for threatened species (Lanier et al., 2016). We found only a few simulation studies using regional-scale populations. For example, Ene et al. (2016) compared the performances of above-ground biomass estimation methods at a regional scale. Our study demonstrates the use of a simulation method to 
Table 1. Estimated optimal sample size and estimated survey costs for 5\%, $10 \%$ and $20 \%$ level of precision with StRS and GRTS. Optimal sample size is computed for each stratum separately, values for the two survey designs are then compared with paired Wilcoxon test.

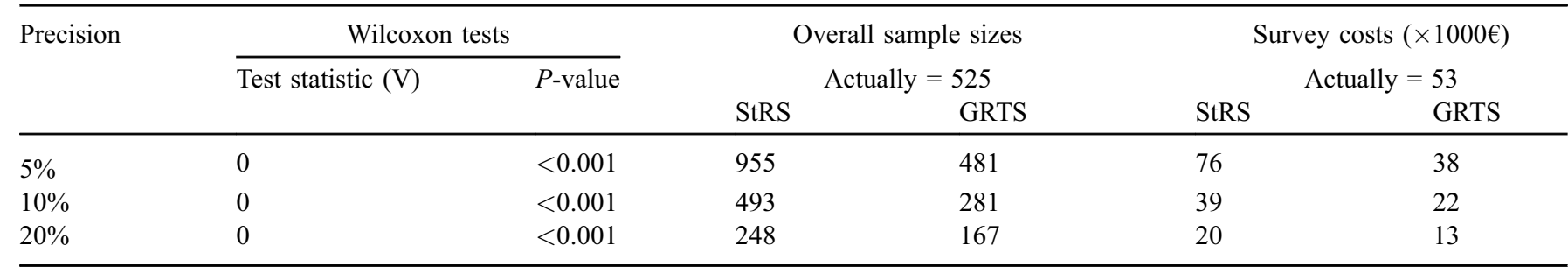

assist in designing a survey of a benthic lagoon population. In addition, Defeo (2011) pointed out the paradox that in reactions to the environment, the structure of regional populations as well as their dynamics are among the most poorly understood; however, commercially exploited bivalve populations should be relatively easy to study (located close to the shore, no or limited animal movements). Our study provides a method to implement or optimize field studies and surveys. We cannot deny that some bias can occurs between the real population and the semi-virtual population we simulated. This bias can be due to the choice of kriging parameters and to gear efficiency during field sampling.

This study demonstrates that for clam population monitoring surveys in the Arcachon Bay, GRTS should prove more efficient than the current survey design (i.e. StRS). We observed in our study that the cost advantage of GRTS compared with StRS increased as the desired level of precision increased (where $5 \%$ precision is higher than $10 \%$ precision, etc.). In our simulation results, the relative similarity in optimum sample size across different sized areas may be a result of different patterns of spatial autocorrelation in different stratum, a topic to be considered further. It seems that the total area of the stratum had less effect on the precision than the heterogeneity of the clam population within the strata. Indeed, the optimal sample size defined by our methodology is a fixed minimal in each stratum. However, we caution that this finding is for this study only, where there is high heterogeneity in clam distribution, irrespective of the size and location of the strata. It is possible that each stratum includes parts with very high clam abundance and others without clams despite the best efforts to delineate homogeneous areas. This hypothesis is based on previous bivalve studies which found that clams often are patchily distributed (e.g. Kalyagina, 1995; Armonies, 1996).

Surveys for populations with high heterogeneity are an ongoing area of research. For example, McGarvey et al. (2016) suggested that systematic survey designs are superior to random designs for clustered populations, and Christianson and Kaufman (2016) highlighted that estimates of heterogeneity can be obtained with a well-chosen survey design. It seems important to have an idea of the heterogeneity and the aggregation of the studied variable or population in order to choose an appropriate survey design. However, complex designs such as GRTS have not been tested yet in benthic populations in a lagoon area. This hypothesis of nonhomogeneous clam distribution in Arcachon Bay will be the subject of a future study.

The applied issue highlights that even if GRTS surpasses classical StRS in terms of requiring a smaller total number of samples, it is important to keep in mind that having more samples in both designs led to better precision in the clam population estimation. Countering that, having more samples leads to higher costs. Alternatively, relying on fewer samples involves a loss of precision but produces a substantial reduction in total survey costs. Comparing the simulated studied designs results and the actual precision from this field survey is not an easy task considering that this field survey use a proportional to the strata surface size survey effort and so achieve different precisions for each stratum while, in the simulated study, the achieved precision is the same for all strata. With the 2012 clam survey in Arcachon Bay, some strata had very good estimated precision $(2.5 \%)$ but others were far worse $(\sim 50 \%)$. We could average these values but this would hide this heterogeneity. Another issue with the current field design is that in the smallest strata, and because the number of sample stations is chosen proportional to the size of the stratum, there are too few stations to calculate a reliable estimate of within-stratum precision. Conversely, in the largest strata, proportional sampling results in very high survey effort with only a marginal benefit in precision. Our proposed methodology reveal that with more constant effort among strata we should improve the estimation of precision, and standardize precision across all strata in the Arcachon Bay.

The final decision of which survey design should be used in future surveys is for the commercial fishers to decide. The applied issues highlight that commercial fishers have to make a choice between overall survey cost and precision. The tradeoff is the following: the survey cost can be lowered but it will reduce precision, or the survey cost can stay as it was with a gain in precision.

\section{Conclusion: perspectives}

Our simulation study suggests that GRTS would be more efficient than StRS (based on the 2012 clam survey). We assume that the Manila clam population shows some spatial heterogeneity in their distribution within Arcachon Bay. It is also possible that some temporal heterogeneity may exist. These aspects will be tested in the near future by using our methodology to include other years of the monitoring survey (2003, 2006, 2008, 2010 and 2014) (Caill-Milly et al., 2003, 2006, 2008; Sanchez et al., 2010, 2014). After conducting this work, the most appropriate design will be discussed with the stakeholders and the recommended sample size for each stratum will be set for future surveys, the next one being scheduled for 2018 .

This first study confirms the possibility of improving clam monitoring. GRTS appears to be an efficient survey design that 
should be used instead of StRS. We note that sample design is a rapidly evolving field of science and other advanced spatially balanced designs have already been described, despite limited field testing (e.g. Robertson et al., 2013; Brown et al., 2015). We will watch this emerging area of research for more ways to improve clam monitoring.

Acknowledgements. Data were collected in the context of the Manila clam monitoring programme financed by the French institute Ifremer, European grants (IFOP - instrument Financier d'Orientation de la Pêche and FEP - Fonds Européens pour la Pêche), the French government (MEEM Ministère de l'Environnement, de l'Energie et de le Mer), Aquitaine Regional Council, Gironde General Council and professional fishing organizations. This work was supported by Ifremer's scientific direction within the framework of site policy grants (DESCARTES 2 project) aiming to reinforce collaborations between Ifremer and regional academic partners. This work was also supported by "Communauté d'Agglomération Pays Basque - Euskal Hirigune Elkargoa" through a thesis grant. We also want to acknowledge the two reviewers of this paper for their good advises and recommendations.

\section{References}

Albert CH, Yoccoz NG, Edwards TC, Graham CH, Zimmermann NE, Thuiller W. 2010. Sampling in ecology and evolution - bridging the gap between theory and practice. Ecography 33: 1028-1037.

Armonies W. 1996. Changes in distribution patterns of 0-group bivalves in the Wadden Sea: byssus-drifting releases juveniles from the constraints of hydrography. J Sea Res 35: 323-334.

Auby I. 1993. Evolution de la richesse biologique du Bassin d'Arcachon (Rapport de contrat No. 15144), Ifremer, France.

Auby I, Labourg PJ. 1996. Seasonal dynamics of Zostera noltii Hornem. in the bay of Arcachon (France). J Sea Res 35: 269-277.

Bald J, Borja A, Muxika I, Franco J, Valencia V. 2005. Assessing reference conditions and physico-chemical status according to the European Water Framework Directive: a case-study from the Basque Country (Northern Spain). Mar Pollut Bull 50: 1508-1522.

Berthou P, Huet J, Noel P, Jezequel M, Fifas S. 1997. Etude de la pêcherie de palourdes du Golfe du Morbihan (Rapport No. 38340), Ifremer, France.

Bertignac M, Auby I, Foucard J, Martin S, De Montaudouin X, Sauriau P. 2001. Evaluation du stock de palourdes du bassin d'Arcachon (Rapport de contrat No. 21658), Ifremer, France.

Bidegain G, Bárcena JF, García A, Juanes J.A. 2015. Predicting coexistence and predominance patterns between the introduced Manila clam (Ruditapes philippinarum) and the European native clam (Ruditapes decussatus). Estuar Coast Shelf Sci 152: 162-172.

Bivand R, Pebesma E, Gomez-Rubio V. 2013. Applied spatial data analysis with R, 2nd edn., Springer, New York.

Bouchet JM, Deltreil JP, Manaud F, Maurer D, Trut G. 1997. Etude Intégrée du Bassin d'Arcachon-Synthèse (Rapport No. 19399), Ifremer, France.

Brown JA, Robertson BL, McDonald T. 2015. Spatially balanced sampling: application to environmental surveys, in: Spat Stat Conf 2015, Vol. 27, pp. 6-9.

Caill-Milly N, de Casamajor MN, Lissardy M, Sanchez F, Morandeau G. 2003. Évaluation du stock de palourdes du bassin d'ArcachonCampagne 2003 (Rapport de contrat No. 17801).
Caill-Milly N, Duclercq B, Morandeau G. 2006. Campagne d'évaluation du stock de palourdes du bassin d'Arcachon-Année 2006 (Rapport No. 2218), Ifremer, France.

Caill-Milly N, Bobinet J, Lissardy M, Morandeau G, Sanchez F. 2008. Campagne d'évaluation du stock de palourdes du bassin d'Arcachon-Année 2008 (Rapport de contrat No. 17800).

Caill-Milly N, Bru N, Mahé K, Borie C, D’Amico F. 2012. Shell shape analysis and spatial allometry patterns of Manila clam (Ruditapes philippinarum) in a mesotidal coastal lagoon. $J$ Mar Biol 2012: 11.

Carlton JT, Thompson JK, Schemel LE, Nichols FH. 1990. Remarkable invasion of San Francisco Bay (California, USA), by the Asian clam Potamocorbula amurensis. I. Introduction and dispersal. Mar Ecol Prog Ser 66: 81-94.

Christianson DS, Kaufman CG. 2016. Effects of sample design and landscape features on a measure of environmental heterogeneity. Methods Ecol Evol 7: 770-782.

Conn PB, Moreland EE, Regehr EV, Richmond EL, Cameron MF, Boveng PL. 2016. Using simulation to evaluate wildlife survey designs: polar bears and seals in the Chukchi Sea. $R$ Soc Open Sci 3: $150-561$.

Dang C. 2009. Dynamique des populations de palourdes japonaises (Ruditapes philippinarum) dans le bassin d'Arcachon: conséquences sur la gestion des populations exploitées, Thèse de doctorat, Bordeaux 1.

Davidson K, Dudas SE. 2016. Microplastic Ingestion by wild and cultured Manila clams (Venerupis philippinarum) from Baynes Sound, British Columbia. Arch Environ Contam Toxicol 71: $147-156$.

De Montaudouin X, Kisielewski I, Bachelet G, Desclaux C. 2000. A census of macroparasites in an intertidal bivalve community, Arcachon Bay, France. Oceanol Acta 23: 453-468.

De Montaudouin X, Lucia M, Binias C, Lassudrie M, Baudrimont M, Legeay A, Raymond N, Jude-Lemeilleur F, Lambert C, Le Goic N. 2015. Why is Asari (= Manila) clam Ruditapes philippinarum fitness poor in Arcachon Bay: a meta-analysis to answer? Estuar Coast Shelf Sci 179: 226-235.

Defeo O. 2011. Sandy beach fisheries as complex social-ecological systems: emerging paradigms for research, management and governance, in: Presented at the Sandy beaches and Coastal Zone Management, Proceedings of the Fifth International Symposium on Sandy Beaches, Travaux de l'Institut Scientifique, Rabat, série générale, pp. 111-112.

Ene LT, Næsset E, Gobakken T. 2016. Simulation-based assessment of sampling strategies for large-area biomass estimation using wall-to-wall and partial coverage airborne laser scanning surveys. Remote Sens Environ 176: 328-340.

Gosling E. 2008. Bivalve molluscs: biology, ecology and culture. Oxford: Wiley-Blackwell.

Goulletquer P, Bacher C. 1988. Empirical modelling of the growth of Ruditapes philippinarum by means of non linear regression on factorial coordinates. Aquat Living Resour 1: 141-154.

Gray CA. 2016a. Tide, time and space: Scales of variation and influences on structuring and sampling beach clams. J Exp Mar Biol Ecol 474: 1-10.

Gray CA. 2016b. Assessment of spatial fishing closures on beach clams. Glob Ecol Conserv 5: 108-117.

Gray CA, Johnson DD, Reynolds D, Rotherham D. 2014. Development of rapid sampling procedures for an exploited bivalve in the swash zone on exposed ocean beaches. Fish Res 154: 205-212.

Guillera-Arroita G, Ridout MS, Morgan BJ. 2010. Design of occupancy studies with imperfect detection. Methods Ecol Evol 1: 131-139. 
Jacobs SE, Gaeuman W, Weeber MA, Gunckel SL, Starcevich SJ. 2009. Utility of a probabilistic sampling design to determine bull trout population status using redd counts in basins of the Columbia River plateau. North Am J Fish Manag 29: 1590-1604.

James RJ, Fairweather PG. 1996. Spatial variation of intertidal macrofauna on a sandy ocean beach in Australia. Estuar Coast Shelf Sci 43: 81-107.

Jensen A, Humphreys J, Caldow R, Grisley C, Dyrynda P. 2004. Naturalization of the Manila clam (Tapes philippinarum), an alien species, and establishment of a clam fishery within Poole Harbour, Dorset. J Mar Biol Assoc UK 84: 1069-1073.

Juanes JA, Bidegain G, Echavarri-Erasun B, Puente A, García Ana, García Andrés, Bárcena JF, Álvarez C, García-Castillo G. 2012. Differential distribution pattern of native Ruditapes decussatus and introduced Ruditapes phillippinarum clam populations in the Bay of Santander (Gulf of Biscay): considerations for fisheries management. Ocean Coast Manag 69: 316-326.

Kalyagina E. 1995. Distribution and population structure of commercial bivalves Ruditapes philippinarum and Mya arenaria in Bousse Lagoon(southern Sakhalin). Russ J Mar Biol 20: 164-168.

Kenkel N, Juhász-Nagy P, Podani J. 1990. On sampling procedures in population and community ecology, in: Progress in theoretical vegetation science, Springer, Netherlands, pp. 195-207.

Kincaid TM, Olsen AR. 2015. spsurvey: spatial survey design and analysis. R package version 3.1.

Kingston PF. 2009. Grabs for shelf benthic sampling, in: J.H. Steele (Ed.), Encyclopedia of ocean sciences, 2nd edn., Academic Press, Oxford, pp. 70-79.

Kombiadou K, Ganthy F, Verney R, Sottolichio A. 2014. Modelling the effects of Zostera noltei meadows on sediment dynamics: application to the Arcachon lagoon. Ocean Dyn 64: 1499-1516.

Lanier WE, Bailey LL, Muths E. 2016. Integrating biology, field logistics, and simulations to optimize parameter estimation for imperiled species. Ecol Model 335: 16-23.

Le TC, Kang HS, Hong HK, Park KJ, Choi KS. 2015. First report of Urosporidium sp., a haplosporidian hyperparasite infecting digenean trematode Parvatrema duboisi in Manila clam, Ruditapes philippinarum on the west coast of Korea. J Invertbr Pathol 130: 141-146.

Le treut y. la palourde. 1986. Anatomie, biologie, elevage, peche, consommation, inspection sanitaire, these de doctorat, Universite de nantes, ecole nationale veterinaire.

Li M, Xu T, Zhou Q. 2012. Development of python-based ArcGIS tools for spatially balanced forest sampling design, in: Presented at the 2012 National Conference on Information Technology and Computer Science. Hong Kong: Atlantis Press, pp. 939-942.

MacKenzie DI. 2006. Occupancy estimation and modeling: inferring patterns and dynamics of species occurrence. Oxford: Academic Press.

MacKenzie DI, Royle JA. 2005. Designing occupancy studies: general advice and allocating survey effort. J Appl Ecol 42: 1105-1114.

McGarvey R, Burch P, Matthews JM. 2016. Precision of systematic and random sampling in clustered populations: habitat patches and aggregating organisms. Ecol Appl 26: 233-248.

Melià P, De Leo G, Gatto M. 2004. Density and temperaturedependence of vital rates in the Manila clam Tapes philippinarum: a stochastic demographic model. Mar Ecol Prog Ser 272: 153-164.

Moore AL, McCarthy MA. 2016. Optimizing ecological survey effort over space and time. Methods Ecol Evol 7: 891-899.

Olu K, Duperret A, Sibuet M, Foucher JP, Fiala-Médioni A. 1996. Structure and distribution of cold seep communities along the
Peruvian active margin: relationship to geological and fluid patterns. Mar Ecol Prog Ser 132: 109-125.

Paillard C, Allam B, Oubella R. 2004. Effect of temperature on defense parameters in Manila clam Ruditapes philippinarum challenged with Vibrio tapetis. Dis Aquat Organ 59: 249-262.

Park KI, Choi KS. 2001. Spatial distribution of the protozoan parasite Perkinsus sp. found in the Manila clams, Ruditapes philippinarum, in Korea. Aquaculture 203: 9-22.

Pebesma E, Bivand R. 2005. Classes and methods for spatial data in R. R News 5: 9-13.

Pitel M, Savina M, Fifas S, Berthou P. 2004. Evaluations locales des populations de bivalves dans le golfe de normand breton. Résultats de la campagne BIVALVES2002 (Rapport No. 4609), Ifremer, France.

Plus M, Maurer D, Stanisière J, Dumas F. 2006. Caractérisation des composantes hydrodynamiques d'une lagune mésotidale, le Bassin d'Arcachon (Rapport No. 2352), Ifremer, France.

Pranovi F, Franceschini G, Casale M, Zucchetta M, Torricelli P, Giovanardi O. 2006. An ecological imbalance induced by a nonnative species: the Manila clam in the Venice lagoon. Biol Invasions 8: 595-609.

$\mathrm{R}$ Core Team. R: A language and environment for statistical computing, R Foundation for Statistical Computing, Vienna, Austria, 2014.

Renard D, Bez N, Desassis N, Beucher H, Ors F, Laporte F. 2014. RGeostats: The Geostatistical package [11.0.1]. Paris: MINES ParisTech/ARMINES.

Robert R, Trut G, Laborde J. 1993. Growth, reproduction and gross biochemical composition of the Manila clam Ruditapes philippinarum in the Bay of Arcachon, France. Mar Biol 116: 291-299.

Robertson B, Brown J, McDonald T, Jaksons P. 2013. BAS: balanced acceptance sampling of natural resources. Biometrics 69: 776-784.

Sanchez F, Caill-Milly N, Lissardy M, De Casamajor MN, Morandeau G. 2010. Campagne d'évaluation du stock de palourdes du bassin d'Arcachon (Rapport de contrat No. 16331), Ifremer, France.

Sanchez F, Caill-Milly N, De Casamajor Marie-Noelle LM. 2012. Campagne d'évaluation du stock de palourdes du bassin d'Arcachon (Rapport de contrat No. 24114), Ifremer, France.

Sanchez F, Caill-Milly N, Lissardy M, Bru N. 2014. Campagne d'évaluation de stock de palourdes du bassin d'Arcachon (Rapport No. 34383), Ifremer, France.

Särndal CE, Thomsen I, Hoem JM, Lindley D, Barndorff-Nielsen O, Dalenius T. 1978. Design-based and model-based inference in survey sampling [with discussion and reply]. Scand J Stat 5: 27-52.

Soudant P, Paillard C, Choquet G, Lambert C, Reid H, Marhic A, Donaghy L, Birkbeck T. 2004. Impact of season and rearing site on the physiological and immunological parameters of the Manila clam Venerupis (= Tapes, $=$ Ruditapes) philippinarum. Aquaculture 229: 401-418.

Stehman SV, Overton WS. 1994. Environmental sampling and monitoring, in: Handbook of statistics. Amsterdam: Elsevier, pp. 263-306.

Stevens DL, Olsen AR. 1999. Spatially restricted surveys over time for aquatic resources. J Agric Biol Environ Stat 4: 415-428.

Stevens DL, Olsen AR. 2003. Variance estimation for spatially balanced samples of environmental resources. Environmetrics 14: 593-610.

Stevens DL, Olsen AR. 2004. Spatially balanced sampling of natural resources. J Am Stat Assoc 99: 262-278.

Talley DM, Talley TS, Blanco A. 2015. Insights into the establishment of the Manila clam on a tidal flat at the southern end of an introduced range in southern California, USA. PLoS ONE 10: e0118891. 
Tamayo D, Ibarrola I, Cigarría J, Navarro E. 2015. The effect of food conditioning on feeding and growth responses to variable rations in fast and slow growing spat of the Manila clam (Ruditapes philippinarum). J Exp Mar Biol Ecol 471: 92-103.

Tamura T. 1970. Marine aquaculture, National Science Foundation, Washington.

Thompson SK. Sampling, 3rd edn. New York: John Wiley \& Sons, Inc., 2012.
Walker RL, Tenore KR. 1984. The distribution and production of the hard clam, Mercenaria mercenaria, in Wassaw Sound, Georgia. Estuaries 7: 19-27.

Yoccoz NG, Nichols JD, Boulinier T. 2001. Monitoring of biological diversity in space and time. Trends Ecol Evol 16: 446-453.

Zhao G, Hoffmann H, Yeluripati J, Xenia S, Nendel C, Coucheney E, Kuhnert M, Tao F, Constantin J, Raynal H. 2016. Evaluating the precision of eight spatial sampling schemes in estimating regional means of simulated yield for two crops. Environ Model Softw 80: $100-112$.

Cite this article as: Kermorvant C, Caill-Milly N, D'Amico F, Bru N, Sanchez F, Lissardy M, Brown J. 2017. Optimization of a survey using spatially balanced sampling: a single-year application of clam monitoring in the Arcachon Bay (SW France). Aquat. Living Resour. 30 : 37 